\title{
Effectiveness of Advanced Collaboration Tools on Crew Communication in Reduced Crew Operations
}

\author{
Sarah V. Ligda ${ }^{1}$, Ute Fischer ${ }^{2}$, Kathleen Mosier ${ }^{3}$, \\ Michael Matessa ${ }^{4}$, Vernol Battiste $^{1}$, and Walter W. Johnson ${ }^{5}$ \\ ${ }^{1}$ San José State University, San José, California, USA \\ \{sarah.v.ligda, vernol.battiste\}@nasa.gov \\ ${ }^{2}$ Georgia Institute of Technology, Atlanta, Georgia, USA \\ ute.fischer@gatech.edu \\ ${ }^{3}$ San Francisco State University, San Francisco, California, USA \\ kmosier@sfsu.edu \\ ${ }^{4}$ Rockwell-Collins, Cedar Rapids, Iowa, USA \\ mpmatess@rockwellcollins.com \\ ${ }^{5}$ NASA Ames Research Center, Moffett Field, California, USA \\ walter.w.johnson@nasa.gov
}

\begin{abstract}
The present research examines operational performance and verbal communication in airline flight crews under reduced crew operations (RCO). Eighteen two-pilot crews flew six scenarios under three conditions; one condition involved current-day operations while two involved RCO. In RCO flights, the Captain initially operated the simulated aircraft alone but could request remote crewmember support as off-nominal events occurred and workload was expected to increase. In one of the two RCO conditions, crewmembers were provided with advanced prototype collaboration tools designed to alleviate difficulties in crew coordination. Crews successfully solved all challenging events without accident and analyses of operational performance did not reveal any differences among the three conditions. In RCO flights, crew communication increased when tools were available relative to flights in which they were not; specifically, there were more acknowledgements and decision-making communications. These results suggest the collaboration tools enable higher degrees of crewmember awareness and/or coordination during distributed operations.
\end{abstract}

Keywords: NextGen, Reduced Crew Operations, Single Pilot Operations, Distributed Teams, Crew Resource Management, CRM tools

\section{Introduction}

The aim of the NextGen Air Transportation System is to increase the efficiency and capacity of the U.S. National Airspace System [1]. New NextGen technologies and services will require that airspace operators rely on automated support tools as traffic density is allowed to expand. Aeronautical equipment manufacturers and airlines will likely respond as well, taking advantage of a new system-wide infrastructure by adjusting their own aviation technology, product designs, and standard operating procedures to fit the modernized airspace.

We can also expect other innovations to occur as a result of NextGen. As flight decks become increasingly automated and communication media more advanced, 
crew functions may be adapted to operate under distributed environments. A redistribution of crew resources could provide many benefits to support NextGen operations while also reducing expenses, such as (1) greater flexibility and specialization of operators adapted to support and solve problems in specific operations (2) consolidated operating procedures in low-workload, nominal phases of flight, and (3) reduced operating costs and fuel savings as a result of smaller cockpits and less overnight accommodations. Many technological and feasibility dimensions are under investigation for this distributed Reduced Crew Operations (RCO) concept (see [2] for initial considerations). One challenge is retaining critical elements involved in crew functioning, especially the many facets of interaction that involve physical presence (e.g., visual monitoring of crewmember activity and visual updates).

\subsection{Importance of Crew Collaboration}

A flight crew's ability to work together effectively as a team is crucial to the safety of commercial aviation. In the $1950 \mathrm{~s}$, this team component was initially overlooked as single pilot flight on piston airplanes expanded to involve more complex, multioperator procedures on larger jet airliners. As operations of the more stable airliners grew, aviation accidents due to mechanical issues dropped sharply. Consequently, human error resulting from poor intra-crew processes was exposed as the new primary barrier to further increasing aviation safety [3]. Despite improvements to cockpit interfaces and more rigorous operator training throughout the 1960s and 1970s, fatalities from U.S. commercial and charter flight accidents did not decline. Instead, fatality rates remained fairly stable during this period, typically claiming three to five lives per 100,000 flight hours, or an average of roughly 240 people per year $[4,5]$.

Beginning in the 1970s, insight from pilot interviews and accident investigations revealed safety-critical errors may be linked to crew coordination and communication rather than issues with individual operational skill [3]. Once this connection was established, researchers started to investigate team skills that promoted effective teamwork to mitigate these errors. Specific strategies were identified and refined, such as the development of effective team workload management (e.g., using low-workload periods to prepare for upcoming tasks), and the use of pre-flight safety briefings to define responsibilities and encourage an open crew climate [6]. The practice of what is now known as Crew Resource Management (CRM) was found to be so essential to safe airspace operations that after March 1999, the FAA barred all U.S. commercial airline companies from utilizing pilots, flight attendants, or dispatchers that had not received training in these skills [7].

With CRM practices and other improvements in air travel, aircraft safety has shown signs of improvement in recent years. In comparison to fatality rates described earlier, the past decade's fatality ratings have dropped to an average of 0.10 fatalities per 100,000 flight hours (2003-2012 reports, 14 CFR Part 121 and 135 operations combined [8]). As we continue to develop concepts of operation to best fit future needs while maximizing all available resources in NextGen, we must prioritize safety by keeping accident and fatality statistics at or below current levels. We have thus focused our initial RCO efforts on the design of an enhanced distributed flight crew environment that retains the qualities of effective CRM and specifically avoids systems that revert back to largely independent, separated operators who just happen to 
be working on the same flight. Our research proceeded in two phases: first we identified the basic challenges that arise when crewmembers are spatially separated, and then we developed tools and procedures designed to overcome these barriers and enable effective distributed flight crews.

\subsection{Components of Crew Resource Management}

Many professional contexts today require that operators not only have necessary technical skills, but also are able to work effectively in teams. As a result, professional training also includes instruction in teamwork that is designed to enhance communication and decision-making. For instance, the airline industry instituted CRM training to develop in its operators proficient "team building and maintenance, information transfer, problem solving, decision-making, maintaining situation awareness, and dealing with automated systems" [9]. Airline CRM training programs aim to raise operator awareness concerning the dynamics of team interaction through initial indoctrination, and then target effective team interaction elements through recurrent practice and feedback with ongoing reinforcement.

Contributions to these training programs stem from research designed to specify and quantify individual behaviors that impact team functioning. One approach is to classify the types of communication to tap team members' shared situation and team models; specifically, to examine the extent to which team members have similar or compatible mental representations concerning their task, their operational environment, and their individual and joint roles and responsibilities [10]. This approach has identified communication patterns associated with high and low task performance. For instance, researchers observed that high performing crews talked more about plans and strategies as they coped with an emergency situation, and that Captains in high performing crews were explicit in allocating roles to crewmembers [6]. In the present research, we use crew communication analysis to evaluate a set of collaboration tools specifically designed to mitigate CRM problems found in prior distributed flight operations research.

\subsection{Prior Reduced Crew Operations Research}

Our first RCO study was conducted with the goal of understanding differences in the task and team performance of crews who were physically separated when compared to collocated [11]. In this study, pilots either sat next to each other in a low-fidelity flight deck (collocated), or sat separately in one of two synchronized flight decks with an audio intercom for communication (distributed). Crews then flew challenging scenarios in current-day operations while we measured performance and pilot behavior.

No differences in flight performance were found between the two conditions. However, analysis of video recordings revealed that there were more instances of pilot confusion in the distributed condition than in the collocated condition. Specifically, pilots were unsure about planned and completed actions by the other crewmember and expressed confusion about location of information on airspace charts and briefing materials. These findings suggest that visual cues that are present in a collocated environment critically support pilots' teamwork. Based on these findings and feedback from the pilot participants, we developed tools designed to reestablish this 
critical set of information. The current research examines the effectiveness of these advanced tools in facilitating interaction by analyzing verbal communication that relates to crew functioning.

\section{Method}

\subsection{Participants and Design}

Participants were 36 airline pilots with ATP certification under 14 CFR Part 121. Seventy-eight percent of the two-pilot crews consisted of current (or recently retired) employees from different U.S. airlines. Five pilots were retired (range of 2 to 16 months).

The study design had two fixed factors (Crew Position and Operational Configuration) and two random factors (Scenario and Crew). However, not all of these factors are critical to the current research objectives. As a result, all present analyses will collapse across Crew Position and focus primarily on a subset of data featuring a comparison of communications between two levels of Operational Configuration (for a more complete report, see [12]).

The Operational Configuration factor reflected operational roles, physical configuration, and technological capabilities. There were three conditions: current-day operations (Baseline) in which both participants operated on the flight deck, and two distributed RCO conditions in which participants were physically separated. In both RCO conditions, the Captain remained on the flight deck and the First Officer moved to a prototype ground station to provide remote support to the Captain as needed. In the RCO No Collaboration Tools condition (NCT), an audio intercom was provided to aid in remote crew interactions. In the RCO with Collaboration Tools condition (CT), an audio intercom and a set of collaboration tools were provided to aid in interactions.

\subsection{Technological Capabilities}

To operate the high-fidelity Boeing 737-900 flight simulator as a distributed crew, NCT flights had a second set of primary flight deck controls and an audio intercom. CT flights had the same capabilities and the Collaboration Tools described below.

EFB and Audio. In both NCT and CT conditions, participants were each provided with an Electronic Flight Bag (EFB) that contained approach plates and charts. An audio intercom allowed for voice communication between the cab and ground station.

Collaboration Tools: CRM Indicators. In the CT condition, six custom-made indicators functioned as devices for tracking critical roles and actions of the crew. On the flight deck, the indicators were implemented with touch-sensitive LED panels. Figure 1 shows the speed, heading, and altitude indicators located below the corresponding controls on the MCP. The Pilot Flying indicator was located to the left of the MCP, and CDU and radio/ATC indicators were located above the CDUs. On the ground station, the indicators were grouped in a single window of a touch-enabled monitor. MCP control actions were displayed on the corresponding indicators with symbols (e.g., up or down arrows indicating changes in MCP speeds) and audio enunciations played when modified (e.g., "speed" enunciated speed changes). Once the action re- 
sulted in a stable value, the value was displayed in the indicator (e.g., "250"). MCP control modifications were simultaneously displayed and enunciated on both stations.

The indicator procedures were also designed to clarify and enhance awareness of current roles and actions. Indicators associated with MCP actions represented the role of Pilot Flying while those associated with CDU actions represented the role of Pilot Monitoring. The text of each indicator was color-coded to signify current roles: green for current duties, white for distributed operator duties. For instance, green MCP indicators and white CDU indicators on the flight deck would imply that the current role of the Captain is Pilot Flying. Concurrently, the ground station would have white MCP indicators and green CDU indicators to signify that the current role of the operator on the ground is Pilot Monitoring. A switch in indicator colors represented a switch in roles, and could only be done by the operator accepting Pilot Flying duties.

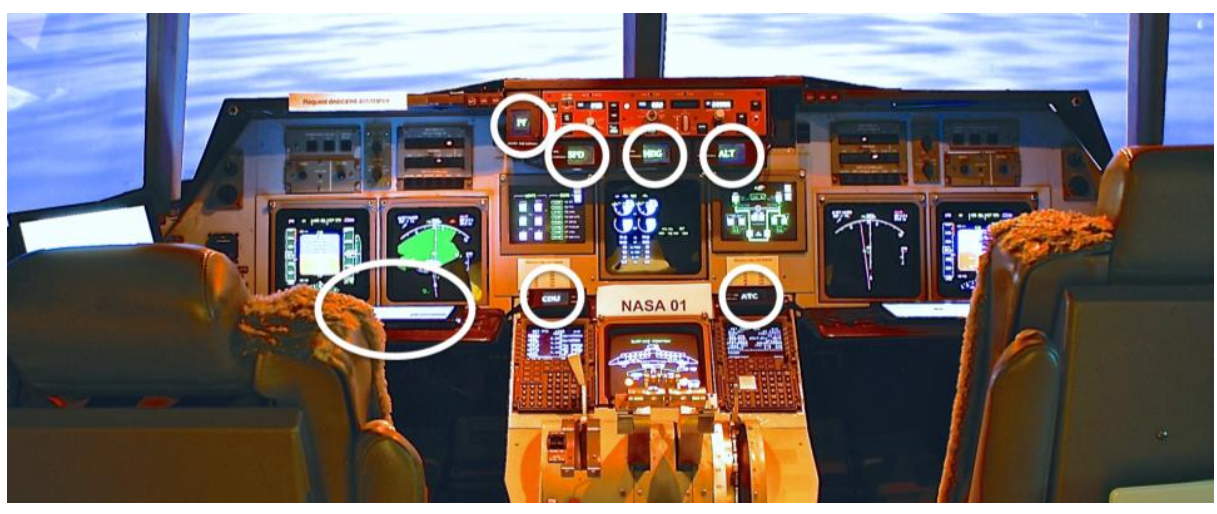

Fig. 1. Flight deck in RCO with Collaboration Tools condition. The six CRM indicators are mounted adjacent to their corresponding instrument panel. Captain's EFB is circled to the left.

Collaboration Tools: Video Feed. In the CT condition, cameras and monitors operated from the side of each station to enable operators with views of their remote partner.

Collaboration Tools: Shared EFB. In the CT condition, operators could toggle between two modes to view EFB information: independent view (separate operator displays) and shared view (synched operator displays). The shared view allowed either operator to access, display, and maneuver (e.g., zoom in) a specific chart or plate with assurance that the same information was displayed on the other EFB. The Captain's EFB also could display weather and traffic from a sector map on the ground station. 


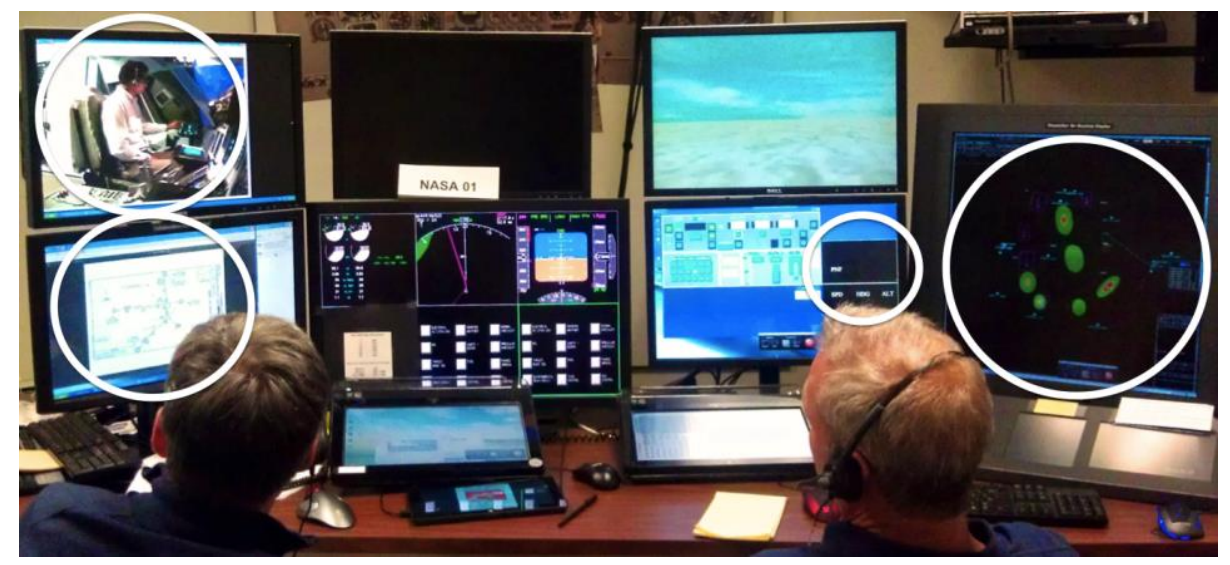

Fig. 2. In RCO with Collaboration Tool condition, the traffic and weather sector map (circled, far right) and the charts and approach plates display (circled, mid-left) can be shared with the Captain, who is shown in the Video Feed (circled, upper left). Ground CRM indictors are to the left of the traffic and weather sector map. The ground operator shown is in CT training.

\subsection{Scenarios and Procedure}

All scenarios involved crew interaction under difficult circumstances. They contained challenging, off-nominal environmental and systems events and secondary challenges that required crews to divert to an airport other than their scheduled destination (see [12] for a more detailed scenario description). A scenario ended once a final decision was made concerning the last scripted event. The Operational Configuration factor (Baseline, NCT, CT) was counterbalanced with the scenarios, which were always in temporal order (e.g., medical emergency scenario always first flight of the day, wheel-well fire scenario always second flight of the day).

Each crew flew under current-day Part 121 standard operating procedures in the Baseline condition. In NCT and CT conditions, the Captain initially operated the aircraft alone. Soon after the onset of the first scripted event (within the first two minutes), the Captain signaled that crewmember support was needed with a verbal request for Dedicated Assistance. The Ground Operator (the First Officer) was then required to support the Captain by performing crewmember duties via a set of remote, synchronized flight deck controls as seen in Figure 2. Operating procedures were similar to current-day while participants were functioning as a crew (with additional Collaboration Tool procedures in CT flights). All Collaboration Tool functions were disabled before the Dedicated Assistance request in CT flights.

\subsection{Communication Coding}

In the RCO conditions (NCT and $\mathrm{CT}$ ), each participant's voice communication was recorded via audio intercom and saved for further analyses. Recordings were then coded using categories based on previous research [10], and subsequently analyzed to compare RCO conditions. Coding categories concerned explicit, task-relevant utterances, with units defined as a clause (that is, a verb and its arguments). Categories 
reflect types of mental models distinguished in the literature; specifically, the task, team and situation knowledge that team members need to have in common to support successful performance $[10,13,14]$. Coding categories were adapted from Orasanu and Fischer [6] who observed that high and low performance by flight crews was associated with distinct communication patterns. Table 1 lists each communication category with a brief description and examples.

Table 1. Shared Mental Model Categories Applied to Crew Communication Recordings

\begin{tabular}{|c|c|}
\hline Contribution Category & Example \\
\hline \multicolumn{2}{|l|}{ Acknowledgment: Confirming awareness/recognition } \\
\hline Acknowledgement/Agreement/Concessions & "Alright" \\
\hline Repeats statement as confirmation & "Copy, flight level two nine zero" \\
\hline \multicolumn{2}{|l|}{$\begin{array}{l}\text { Decision-Making: Contribution concerns possible choices, } \\
\text { plans, and their evaluation }\end{array}$} \\
\hline Priorities/Goals & "What airspeed would you like?" \\
\hline Constraints/Evaluation & "I don't mind holding here" \\
\hline Decision/Options & "Heading 270 I think would work" \\
\hline \multicolumn{2}{|l|}{ Situation Model: Contribution addresses critical } \\
\hline information concerning environment or system state & "Master $\mathrm{O}_{2}$ is on" \\
\hline Request for system state, traffic, weather, etc. & "What does the ATIS report?" \\
\hline $\begin{array}{l}\text { Factual statement concerning system state, traffic, etc. } \\
\text { Contribution that adds to shared situation }\end{array}$ & "There's no weather at Denver" \\
\hline Team Mental Model: Contribution's emphasis is on actor & "I just set the flight level to $310 "$ \\
\hline Concerns own/partner's action or knowledge & "I'll get with ATC here" \\
\hline Refers to/directs partner's action & "Just be sure to retract the speed \\
\hline Establishes shared knowledge of item/fact & brake afterward" \\
\hline \multicolumn{2}{|l|}{ Workload: Contribution's emphasis is on task and task } \\
\hline management & "Starting the descent checklist?" \\
\hline Contribution concerns task scheduling/procedures & "We need to do call center" \\
\hline Statement about task requests/requirement/completed & "Checklist complete" \\
\hline \multicolumn{2}{|l|}{ *Communication Problems } \\
\hline Request to clarify/repeat & "What was that?" \\
\hline Coordination problem in speaking (turn-taking) & "Go ahead" \\
\hline Misunderstanding apparently undetected by pilots & \\
\hline *Inaudible: Communications difficult to decipher & ---- \\
\hline
\end{tabular}

\section{Results}

\subsection{Operational Performance}

In all 108 flights, crews successfully solved all challenging events and no accidents occurred. Analyses of the aircraft state data did not reveal any significant differences among the three Operational Configuration conditions (e.g., speed, altitude, heading, pitch). This was expected due to the heterogeneity of the scenario structures. Additional performance measures are listed below in Table 2, including number of times crewmembers changed the destination airport in the Flight Management System 
(FMS), and agreement in final destination airport choice airport when compared with pilot subject matter experts (SME) who assisted in scenario development. No significant effect was found in these measures as a function of Operational Configuration.

Table 2. Means and Standard Deviations of Selected Operational Performance Measures

\begin{tabular}{lllll}
\hline $\begin{array}{l}\text { Operational } \\
\text { Configuration } \\
\text { Condition }\end{array}$ & $\begin{array}{l}\text { Final Airport } \\
\text { Modifications } \\
\text { in FMS }\end{array}$ & $\begin{array}{l}\text { SME Agreement } \\
\text { in Final Airport } \\
\text { Choice }\end{array}$ & $\begin{array}{l}\text { Fuel Used } \\
\text { Per Minute }\end{array}$ & $\begin{array}{l}\text { Time to } \\
\text { Complete } \\
\text { All Events }\end{array}$ \\
\hline $\begin{array}{l}\text { Baseline } \\
2.58\end{array}$ & $78 \%$ & $\begin{array}{l}95.02 \mathrm{lbs} \\
(35.04 \mathrm{lbs})\end{array}$ & $\begin{array}{l}17 \mathrm{~min}, 49 \mathrm{sec} \\
(2 \mathrm{~min}, 43 \mathrm{sec})\end{array}$ \\
$\begin{array}{l}\text { No Collaboration } \\
\text { Tools }\end{array}$ & $\begin{array}{l}0.43) \\
(0.42)\end{array}$ & $81 \%$ & $92.49 \mathrm{lbs}$ & $17 \mathrm{~min}, 37 \mathrm{sec}$ \\
& & & $(22.88 \mathrm{lbs})$ & $(2 \mathrm{~min}, 45 \mathrm{sec})$ \\
$\begin{array}{l}\text { Collaboration } \\
\text { Tools }\end{array}$ & 2.56 & $78 \%$ & $94.66 \mathrm{lbs}$ & $18 \mathrm{~min}, 49 \mathrm{sec}$ \\
\hline
\end{tabular}

A trend towards longer elapsed time in the CT flights suggest that crews took longer to complete all events in the CT condition than the NCT or Baseline condition (from scenario start to final decision in last scripted event). Although this difference is not statistically significant, it is consistent with findings reported in the communication analyses below.

\subsection{Communication Difference as a Function of Collaboration Tool Availability}

Communication coding was done directly from audio recordings using Audacity audio editing software. Four coders were trained to identify units and assign them to the coding categories described in Table 1. Inter-rater reliably was checked for the four coders, and ranged between .76-.90 on units and .75-.80 on categories when compared to the trainer (Fischer). The present analysis focused only on within-crew communication; other communications were not included (e.g., ATC communications, questions for researchers, self-talk, reading of checklists).

Table 3. Means and Standard Deviations of Crew Communication and Time Elapsed Measures

\begin{tabular}{|c|c|c|c|c|c|}
\hline $\begin{array}{l}\text { Reduced Crew } \\
\text { Operations } \\
\text { Condition } \\
\end{array}$ & $\begin{array}{l}\text { Time to Complete } \\
\text { All Events from } \\
\text { DA Request }\end{array}$ & $\begin{array}{l}\text { Time Spent in } \\
\text { Crew Comm. }\end{array}$ & $\begin{array}{l}\text { Percent } \\
\text { DA Time in } \\
\text { Crew Comm. }\end{array}$ & $\begin{array}{l}\text { Total } \\
\text { Comm. } \\
\text { Units }\end{array}$ & $\begin{array}{l}\text { Units } \\
\text { per Min } \\
\text { Rate }\end{array}$ \\
\hline $\begin{array}{l}\text { No Collaboration } \\
\text { Tools }\end{array}$ & $\begin{array}{l}15 \mathrm{~min}, 34 \mathrm{sec} \\
(3 \mathrm{~min}, 0 \mathrm{sec})\end{array}$ & $\begin{array}{l}6 \mathrm{~min}, 40 \mathrm{sec} \\
(1 \mathrm{~min}, 42 \mathrm{sec})\end{array}$ & $43 \%$ & $\begin{array}{l}173.81 \\
(50.11)\end{array}$ & 11.16 \\
\hline $\begin{array}{l}\text { Collaboration } \\
\text { Tools }\end{array}$ & $\begin{array}{l}16 \mathrm{~min}, 20 \mathrm{sec} \\
(3 \mathrm{~min}, 17 \mathrm{sec})\end{array}$ & $\begin{array}{l}7 \mathrm{~min}, 56 \mathrm{sec} \\
(1 \mathrm{~min}, 58 \mathrm{sec})\end{array}$ & $49 \%$ & $\begin{array}{l}198.06 \\
(60.63)\end{array}$ & 12.12 \\
\hline
\end{tabular}

Table 3 presents the results for several measures of communication quantity by RCO condition. As can be seen, measures were generally higher when crews had the Collaboration Tools compared to the No Tool condition. However, only one measure - the time crews spent communicating as they completed all scenario events - was 
statistically significant, $F(1,17)=7.98, p=.01$. Crews talked for 76 seconds longer during CT flights than during NCT flights. The difference between conditions with respect to the number of units approached significance, $F(1,17)=3.25, p=.09$; none of the other measures were significant.

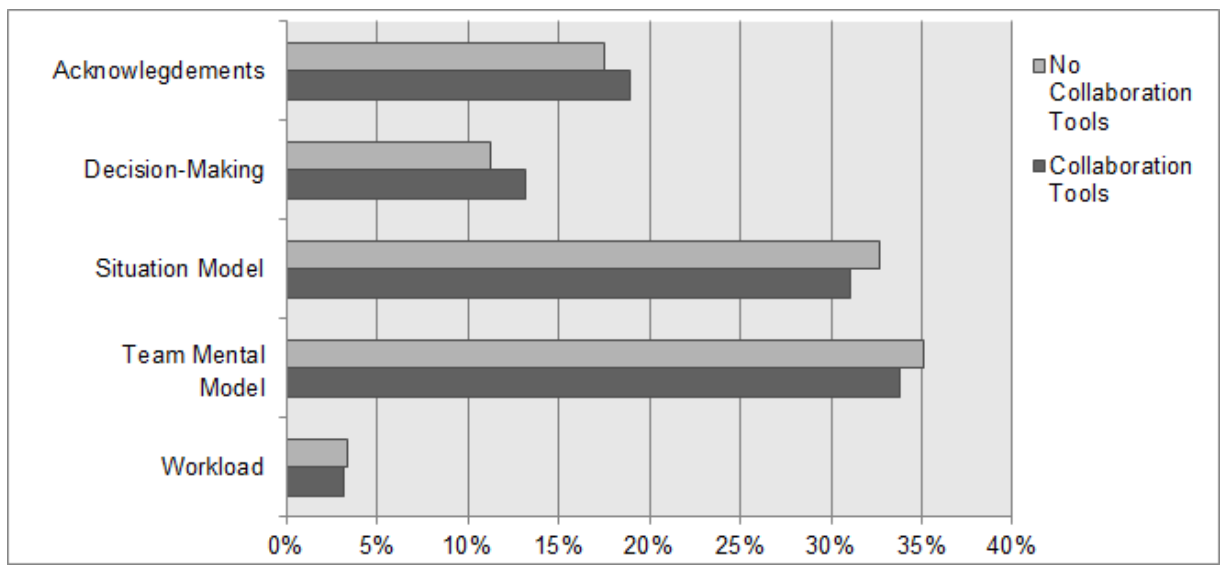

Fig. 3. Distribution of Task-Relevant Communication Categories by RCO condition

In addition to the quantity of crew communication, we also considered its content. Figure 3 shows what aspects of their task, teamwork, or situation that crewmembers addressed in their communications during each of the RCO conditions. A Chi-Square test revealed a significant association between type of communication and availability of collaboration tools, $X^{2}(4, \mathrm{n}=13,324)=18.65, p<.001$. This analysis suggests that when distributed crewmembers could rely on collaboration tools, they were more likely to acknowledge a partner's contribution and engage in decision-making compared to flights during which they did not have the tools. Conversely, in the absence of collaboration tools crewmembers tended to talk more frequently about their situation understanding and their individual and joint actions.

\section{Discussion}

Previous research on teamwork in Reduced Crew Operations (RCO) suggests that distributed members of flight crews lack access to important visual cues, most notably regarding each other's actions [11]. Current-day flight deck technologies do not support collaboration by distributed crewmembers. We therefore developed a set of collaboration tools to fill this need. The impact of these tools on the flight performance of 18 two-pilot crews and their communication was assessed in the present research. In this study, there were two conditions that involved a distributed crew and a baseline condition where crewmembers were collocated. Collaboration tools and a voice intercom were available in one of the distributed conditions; the other condition included only the intercom. The collaboration tools were: (1) CRM indicators representing current piloting roles and control actions (2) EFB displays of airspace information 
mirrored between stations (3) Video feeds showing the distributed crewmember in his/her station.

\subsection{Crew Communication and Collaboration Tool Availability}

The availability of collaboration tools influenced how much and what crewmembers communicated. The presence of tools seemed to have directed crewmembers' attention to their joint responsibility for making safe decisions. They spent more time communicating, and more importantly, they shared more decision-relevant information and were more responsive to each other. Apparently, since they had access to the same airspace information as well as information about their individual actions, they talked less about their current flight situation and teamwork and instead focused on decision-making. In contrast, during flights in which they did not have the tools, crewmembers were apparently more focused on establishing a shared situation understanding and common ground with respect to their teamwork.

However, the presence of collaboration tools may induce a false sense of sharedness insofar as crewmembers may assume that just because visual information is shared, it is also commonly understood. A number of studies have shown that this assumption is not necessarily correct, such as those that found that pilots with comparable experience interpreted identical environmental cues differently and as a result reached different decisions $[15,16]$. In the present research for instance, the information and feedback provided by the collaboration tools in displaying and providing step-by-step updates in coordination, action, or situation may lead crewmembers to verbally condense a series of operations that may have multiple implications and meanings. Findings like these are relevant to RCO operations, in particular if they will involve distributed team members with different professional training. As team members differ in their professional background, their situation understanding may differ accordingly and may lead to misunderstanding and conflict [17, 18, 19]. Future research will need to examine more directly than the present study how collaborative tools affect crewmembers' shared situation understanding, specifically whether they lead to inadequate crew communication and misunderstandings.

\subsection{Operational Performance and Limitations}

The results of the operational performance analyses support prior RCO work that also did not find any performance differences between distributed and collocated flight operations [11]. This absence may be due to a number of limitations that resulted from the exploratory, multi-objective approach of the study, and this may have lessened any observed effect in operational performance among the two RCO conditions that was seen in crew communication and other subjective measures [12]. One likely aspect is that this was our first empirical test of the prototyped tools and their procedures. Further refinement to the collaboration tools with more specific experiments may increase their effectiveness and produce differences in operational performance that were not observed here. For insight that may aid in future development, we solicited participant pilots' feedback on the collaboration tools in debriefing interviews and questionnaires. 
Pilots primarily suggested improving the interfaces and modifying how often the tools presented information. A repeated suggestion to improve the shared EFB display was to develop a tablet application interface in which information is more easily manipulated on small screens and to move away from the desktop computer interface (mirrored from the ground station's desktop). A sizable portion of Captains reported that the Video Feed was distracting at times, which is understandable when considering that many of the ground station's displays were modified or new when compared to a traditional flight deck and thus unfamiliar without the training given to First Officers. Also, a few pilots suggested that the Video Feed would be more useful if it also contained a view that focused on the primary flight deck panels for viewing manipulations as they occurred. The last major improvement suggestion was to lessen the frequency of the CRM enunciations. Future research in the development of these technologies and procedures for an RCO concept of operations will need to consider these suggestions, as well as findings presented here and in parallel reports [12].

\section{References}

1. FAA: NextGen Implementation Plan. Office of NextGen: Federal Aviation Administration, Washington D.C. (2014)

2. Comerford, D., Brandt, S.L., Lachter, J., Wu, S.-C., Mogford, R., Battiste, V., Johnson, W.W.: NASA's Single-Pilot Operations Technical Interchange Meeting: Proceedings and Findings. NASA-CP-2013-216513. NASA Ames Research Center, Moffett Field, CA (2013)

3. Helmreich, R. L., Foushee, H. C.: Why Crew Resource Management? Empirical and Theoretical Bases of Human Factors Training in Aviation. In: Wiener, E. L., Kanki, B. G., Helmreich, R. L. (eds.) Cockpit Resource Management, pp. 3--45. Academic Press, San Diego, CA (1993)

4. NTSB: Annual Review: U.S. Air Carrier Accidents Calendar Year 1966-1968. NTSB/ARC/66-AA--NTSB/ARC/68-AA. National Transportation Safety Board, Washington D.C. (1967-1971)

5. NTSB: Annual Review of Aircraft Accident Data: U.S. Air Carrier Operations, 1968-1979. NTSB/ARC/71-01--01-NTSB/ARC/81-01. National Transportation Safety Board, Washington D.C. (1970-1991)

6. Orasanu, J., Fischer, U.: Team Cognition in the Cockpit: Linguistic Control of Shared Problem Solving. In: Proceedings of the 14th Annual Conference of the Cognitive Science Society, pp. 189--194, Cognitive Science Society (1992)

7. 14 CFR 121.404. In: Code of Federal Regulations, Title 14 Aeronautics and Space, Parts 110-199, pp. 155--197. U.S. Government Publishing Office, Washington D.C. (2014)

8. DOT: National Transportation Statistics. Bureau of Transportation Statistics: U.S. Department of Transportation, Washington D.C. (2014)

9. FAA: AC 120-51E, Crew Resource Management Training. U.S. Department of Transportation: Federal Aviation Administration, Washington D.C. (2004)

10. Orasanu, J. M.: Shared Problem Models and Flight Crew Performance. In: N. Johnston, N. McDonald, N., Fuller, R. (eds.) Aviation Psychology in Practice, pp. 255--285. Ashgate Publishing Group, Aldershot, England (1994) 
11. Lachter, J., Quang V., Dao, Q. V., Battiste, V., Koteskey, R., Matessa, M. Johnson, W.W.: Toward Single Pilot Operations: The Impact of the Loss of Nonverbal Communication on the Flight Deck. HCI-Aero, Santa Clara, CA (2014)

12. Lachter, J., Brandt, S.L., Battiste, V., Ligda, S.V., Matessa, M., Johnson, W.W.: Toward Single Pilot Operations: Developing a Ground Station. HCI-Aero, Santa Clara, CA (2014)

13. Cannon-Bowers, J. A., Salas, E., Converse, S.: Shared Mental Models in Team Decision Making. In: Castellan, N. J. (ed.) Individual and Group Decision Making: Current Issues, pp. 221--246. Lawrence Erlbaum Associates, Hillsdale, NJ (1993)

14. Mathieu, J. E., Heffner, T. S., Goodwin, G. F., Salas, E., Cannon-Bowers, J. A.: The Influence of Shared Mental Models on Team Process and Performance. In: Journal of Applied Psychology, 85, 273--283 (2000)

15. Fischer, U., Orasanu, J., Davison, J.: Why Do Pilots Take Risks? Some Insights from a Think-Aloud Study. In: Cook, M. J. (ed.) Proceedings of the Human Factors of Decision Making in Complex Systems Meeting, pp. 44--46. University of Abertay Press, Dundee, Scotland (2003)

16. Fischer, U., Orasanu, J., Wich, M: Experts Pilots' Perceptions of Problem Situations. Proceedings of the 8th International Symposium of Aviation Psychology, pp. 777--782. The Ohio State University, Columbus, OH (1995)

17. Bearman, C., Paletz, S. B. F., Orasanu, J., Thomas, M. J. W.: The Breakdown of Coordinated Decision Making in Distributed Systems. Human Factors: The Journal of the Human Factors and Ergonomics Society, 52, 173--188 (2010)

18. Davison, J., Orasanu, J.: Pilots' and Controllers' Perceptions of Traffic Risk. 11th International Symposium on Aviation Psychology, Columbus, OH (2001)

19. Mosier, K. L., Rettenmaier, P., McDearmid, M., Wilson, J., Mak, S., Raj, L., Orasanu, J. M.: Pilot/ATC Communication Conflicts: Implications for NextGen. International Journal of Aviation Psychology, 23, 213--226 (2013) 